\title{
INFLUENCE OF MW PRETREATMENT ON MAIN GASIFICATION/COMBUSTION CHARACTERISTICS OF DIFFERENT TYPES OF BIOMASS
}

\author{
Inesa Barmina, Raimonds Valdmanis, Maija Zake \\ Institute of Physics, University of Latvia, Latvia \\ inesa.barmina@lu.lv, raimonds.valdmanis@lu.lv, maija.zake@lu.lv
}

\begin{abstract}
Microwave (mw) pre-treatment of biomass pellets (wood, straw and peat) with $2.45 \mathrm{GHz}$ frequency is provided with the aim to break down the structure of lignocellulosic pellets, activate their thermal decomposition, formation of combustible volatiles $\left(\mathrm{CO}, \mathrm{H}_{2}\right)$ and improve the gasification/combustion characteristics. Gasification/combustion characteristics of mw-activated pellets are tested using a pilot device, which combines a biomass gasifier and a combustor with a heat output up to $5 \mathrm{~kW}$. The complex research of the main gasification/combustion characteristics for raw and mw pre-treated biomass samples includes the time dependent measurements of the weight loss of biomass pellets during thermal decomposition, flame temperature, produced heat energy per mass of burned pellets, combustion efficiency and the composition of the products. Kinetic study of the weight loss rate of pre-treated pellets and composition of volatiles at the outlet of the gasifier confirm that mw pre-treatment of pellets activates the thermal decomposition of the main constituents of biomass (hemicellulose, cellulose and lignin) intensifying the axial flow of combustible volatiles $\left(\mathrm{CO}, \mathrm{H}_{2}, \mathrm{C}_{\mathrm{x}} \mathrm{H}_{\mathrm{y}}\right)$ at the flame base promoting their faster ignition and burnout, which depends on the duration of mw pre-treatment of biomass pellets. The enhanced thermal decomposition of mw pre-treated pellets correlates with increase of the flame temperature during the self-sustaining combustion of volatiles with correlating increase of the total amount of produced heat energy per mass of burned pellets by $18-23 \%$ and the produced heat output from the device by $\sim 24-33 \%$, indicating improved combustion of volatiles. The enhanced burnout of activated pellets is confirmed by a decrease of the air excess ratio in the flame reaction zone with a correlating increase of the average value of the volume fraction of $\mathrm{CO}_{2}$ in the products by about $7-12 \%$.
\end{abstract}

Keywords: biomass, pellets, microwave pre-treatment, gasification, combustion characteristics.

\section{Introduction}

In order to limit the Earth's climate change from combustion of fossil fuels (natural gas, coal, oil), more efficient use of carbon neutral renewable fuels (forestry and agricultural residues) for heat production is becoming more relevant in Europe and the world $[1 ; 2]$. However, the use of renewable sources, especially agricultural or herbaceous residues, for energy production is limited by their low calorific value, high moisture, nitrogen and ash contents in biomass [3]. Combined processes of biomass thermochemical conversion are developed to improve the main combustion characteristics and the composition of the products by co-firing of problematic biomass fuels (agricultural or herbaceous residues) with wood [3; 4] or fossil fuels (gaseous, coal or peat) [5-7]. Moreover, biomass characteristics can be improved by washing, drying, granulation or conversion of biomass into biogas or bioethanol. The results of previous studies suggest that efficient improvement of biomass combustion characteristics can be achieved by microwave pre-processing of biomass residues [8-12], based on the dielectric heating of dipolar molecules of lignocellulose biomass. Vibration of dipolar molecules in electromagnetic field and their thermal heating leads to partial destruction of hemicellulose, cellulose in biomass and promotes faster biomass thermal decomposition $[10 ; 11]$, increasing the yield of gaseous and solid products with enhanced char conversion, while limiting the formation of liquid components [12]. The surface area of the produced char is larger by $\mathrm{mw}$ pretreatment of biomass and almost half of biomass can be converted into combustible gases $\left(\mathrm{H}_{2}, \mathrm{CH}_{4}\right.$, $\mathrm{CO}, \mathrm{CO}_{2}$ ), increasing the yield of the produced bioenergy [12]. The previous investigations of the effect of mw pre-treatment of straw, wood or peat pellets and their mixtures on their thermal decomposition $[13 ; 14]$ confirm that mw pre-treatment of these pellets partially reduces the moisture content of the biomass and breaks down the structure of the biomass constituents (hemicelluloses, cellulose and lignin) determining enhanced formation of combustible volatiles in the gasification zone, completing combustion of volatiles in the flame reaction zone and increasing the heat output from the device. Based on the experience gained in the previous research, the main aim of this study is to assess the effect of mw pre-treatment of wood, straw and peat pellets to achieve the optimal combustion conditions in the flame reaction zone with improved combustion efficiency and the optimal heat output from the device by varying the duration of microwave pre-treatment using the experimental setup with heat output up to $5 \mathrm{~kW}$. 


\section{Materials and methods of the research}

The effect of mw pre-treatment on thermochemical conversion of biomass pellets (wood, peat, wheat straw) was studied using the small-scale periodic operation experimental setup with a heat output up to $5 \mathrm{~kW}$ and the previously developed methodology of experimental measurements [7]. The main components of the setup: a biomass gasifier, two vertical and one T-shaped water-cooled sections of the combustor with the inner diameter $D=88 \mathrm{~mm}$. The total length of the setup $L=1220 \mathrm{~mm}$. The mw pre-treatment of wood, straw and peat pellets was carried out at a frequency $2.45 \mathrm{GHz}$ using a microwave reactor with heat output $700 \mathrm{~W}$. The duration of the mw pre-processing of pellets was varied in a range from $t=120$ to $t=300 \mathrm{~s}$, by varying the total amount of mw energy consumed during the mw pre-treatment of pellets in the range from 0.17 to $0.22 \mathrm{MJ} \cdot \mathrm{kg}^{-1}$ for wood, in the range from 0.20 to 0.44 for straw and from 0.16 up to 0.37 for peat. The mw pre-processing of biomass results in the weight loss of pellets depending on the duration of mw pre-processing and the energy consumed during the mw pre-treatment. The measurements of the weight loss rate of pellets suggest that for equal durations of mw pre-treatment of pellets $(t=220 \mathrm{~s})$ the weight loss of pellets is influenced by their elemental composition. The fastest and the highest weight loss $(\Delta m, \%)$ is observed at mw pre-treatment of straw pellets (up to $25 \%$ ), which predominately refers to exothermal decomposition of hemicellulose, developing at temperature about $570 \mathrm{~K}$ [15]. The weight loss for wood pellets during their endothermal decomposition of hemicellulose at $T \approx 600 \mathrm{~K}$ reaches $12 \%$, while for peat pellets with reduced contents of hemicellulose and cellulose the weight loss rate decreases to $9 \%$ (Fig. 1).

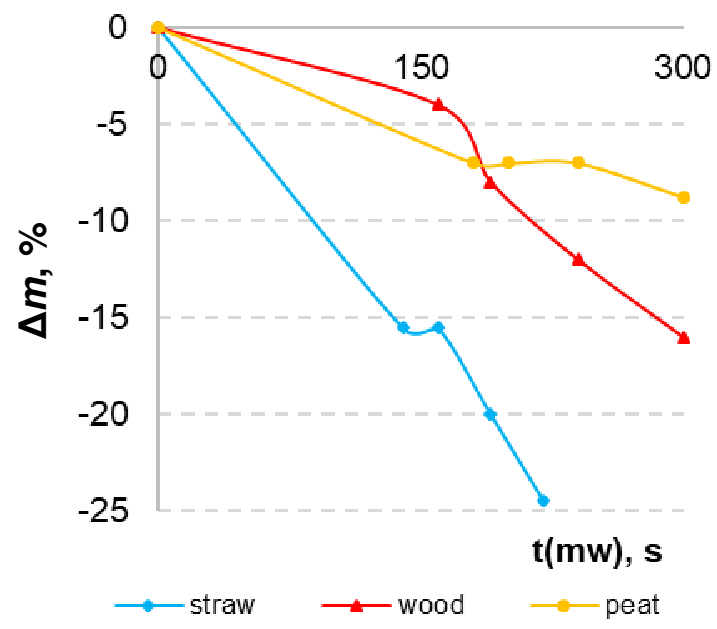

Fig. 1. Effect of $\mathbf{m w}$ pre-treatment duration on the mass loss of biomass pellets

To estimate the effect of mw pre-processing of pellets on their thermochemical conversion, the untreated or mw pre-treated biomass pellets are filled into the gasifier, by limiting the height of the biomass layer for all biomass samples to $120 \mathrm{~mm}$. Because of different mass density of pellets, the average mass of wood pellets filled in the gasifier was varied from $500 \mathrm{~g}$ for untreated pellets to 480 $420 \mathrm{~g}$ for mw pre-treated pellets. The total mass of straw pellets was varied from $450 \mathrm{~g}$ for untreated pellets to $380-340 \mathrm{~g}$ for $\mathrm{mw}$ pre-treated pellets and for peat - from $570 \mathrm{~g}$ to $530-520 \mathrm{~g}$.

To initiate the thermochemical conversion of pre-treated pellets, the propane flame with heat output $0.89 \mathrm{~kW}$ was supplied into the upper part of the biomass layer and was switched off after ignition of volatiles $-t=400 \mathrm{~s}$ for wood and straw pellets, and $t=500 \mathrm{~s}$ for peat pellets. To sustain the biomass thermal decomposition (gasification) and formation of volatiles $\left(\mathrm{CO}, \mathrm{H}_{2}, \mathrm{C}_{\mathrm{x}} \mathrm{H}_{\mathrm{y}}\right)$, primary air was supplied to the lower part of the gasifier at constant rate $301 \cdot \mathrm{min}^{-1}$ and average air excess $\alpha \approx 0.3$ 0.5. To sustain the thermochemical conversion of biomass pellets, the secondary swirling air at constant rate $401 \cdot \mathrm{min}^{-1}$ was supplied into the outlet of the gasifier using 8 tangential nozzles with $d=3.3 \mathrm{~mm}$. The average air excess rate in the combustion zone achieved $\alpha \approx 1.1-1.2$.

All the sections of the combustor are equipped with special holes for introduction of diagnostic tools into the flame and to provide on-line measurements of the main gasification/combustion characteristics. The composition of volatiles $\left(\mathrm{H}_{2}, \mathrm{CO}\right)$ from gas samples $(50 \mathrm{ml})$ was extracted at the 
gasifier outlet $(L / D=-0.9$ from secondary air supply) and analyzed by a Testo 350 gas analyzer with an accuracy $\pm 5 \%$. The flame axial $(u)$ and tangential $(w)$ velocity profiles were measured with the Pitot tube and a Testo 435 flow meter at the distance $L / D=1.6$ from secondary air supply with accuracy $\pm 1 \%$. The temperature of the flame was measured using the Pt/Pt-Rh thermocouple at the distance $L / D=3.2$ with an accuracy $\pm 1 \%$. The composition of emissions $\left(\mathrm{O}_{2}, \mathrm{CO}_{2}, \mathrm{NO}_{\mathrm{x}}, \mathrm{CO}, \mathrm{H}_{2},\right)$, temperature, air excess and the combustion efficiency were measured at the combustor exit $(L / D=11)$ using a gas analyser Testo 350. The measurements of time-dependent variations of the biomass height $(d L / d t)$ in the gasifier with estimation of the biomass weight loss rate $(d m / d t)$ were controlled by a moving rod supplied with a pointer (accuracy $\pm 2 \%$ ). The heat production rates from the gasifier (Pgas), from the vertical primary section of the combustor (P-1) and from the vertical secondary and T-shaped sections of the combustor (P-2) were measured from the calorimetric measurements of cooling water mass flows from each section and the temperatures, which were measured by AD 590 thermo-sensors (accuracy $\pm 2.5 \%$ ) with data registrations by Data Translation DT 9805 data acquisition module.

\section{Experimental results}

As mentioned above, mw pre-treatment of biomass pellets promotes the breakdown of hemicellulose and cellulose structures with different contents for wheat straw, wood and peat biomass pellets. The higher average content of hemicelluloses is observed for wheat straw samples $(21 \div 28 \%)$, while reduced content of hemicelluloses is observed for wood $(23 \div 25 \%)$ and peat $(10 \div 25 \%)$. Moreover, the wood biomass has higher content of cellulose $(41 \div 43 \%)$, with reduced content of cellulose for straw $(24 \div 35 \%)$ and peat $(0 \div 20 \%)$, while the highest lignin content is observed for peat biomass (up to $40 \%)$ in comparison with wood $(28 \div 29 \%)$ and straw $(16 \div 20 \%)$ [11]. Therefore, as follows form Figure 1, higher mass loss during mw pre-processing is observed for straw and wood pellets. The differences in the chemical and elemental composition of the biomass pellets significantly influence the thermal decomposition of pellets.

The comparative analysis of the weight loss rate $(d m / d t)$ for untreated $(\mathrm{mw}=0)$ wood, straw and peat samples has shown that during the primary stage of thermal decomposition $t \approx 300-800 \mathrm{~s}$ (minmax), when mainly endothermic release of light volatiles and water occurs, the highest average weight loss rate is observed for wood pellets from 0.07 to $0.31 \mathrm{~g} \cdot \mathrm{s}^{-1}$ and for straw pellets from 0.04 to $0.28 \mathrm{~g} \cdot \mathrm{s}^{-1}$, the peat pellets with smaller content of hemicellulose and cellulose have less weight loss rate from 0.02 to $0.18 \mathrm{~g} \cdot \mathrm{s}^{-1}$ (Fig. 2, a). During the self-sustaining combustion for all type pellets the average weight loss rate reaches $0.17-0.22 \mathrm{~g} \cdot \mathrm{s}^{-1}$ (max-end). The peat biomass with higher content of lignin is more resistant to thermal decomposition of pellets with the maximum value of weight loss rate (up to $\left.0.39 \mathrm{~g} \cdot \mathrm{s}^{-1}\right)$ during the char conversion stage $(t \approx 2000-2750 \mathrm{~s}$ ). The char conversion stage for straw and wood pellets occurred at $\mathrm{t} \approx 1900-2300 \mathrm{~s}$ with maximum of the weight loss rate for wood up to $0.36 \mathrm{~g} \cdot \mathrm{s}^{-1}$ and for straw - up to $0.30 \mathrm{~g} \cdot \mathrm{s}^{-1}$ (Fig. 2, a).

The mw pre-treatment of pellets with partial destruction of biomass structure leads to faster ignition and decomposition of biomass with increase of the weight loss rate and correlating decrease of the air excess ratio in the flow during primary (min-max) and self-sustaining combustion (max-end) stages (Fig. 2, a, c-d). As can be seen from the Fig. 2, c-d, the dependence of the mw pre-treatment duration of pellets on the weight loss and air excess rates for straw, wood and peat is different. For wheat straw pellets the minimum of air excess rate $\alpha \approx 0.97$ and maximum average weight loss rate $d m / d t=0.27 \mathrm{~g} \cdot \mathrm{s}^{-1}$ is observed at mw pre-treated duration $140 \mathrm{~s}$, for wood pellets the minimum of air excess rate $\alpha \approx 0.65$ and maximum average weight loss rate $0.4 \mathrm{~g} \cdot \mathrm{s}^{-1}$ is observed at duration of mw pre-treatment $240 \mathrm{~s}$, accordingly for peat pellets minimum of air excess $\alpha \approx 0.8$ and maximum average weight loss rate $0.28 \mathrm{~g} \cdot \mathrm{s}^{-1}$ is observed at $t=240 \div 300 \mathrm{~s}$. Besides, increasing of the mass loss rate during thermal decomposition of mw pre-treated pellets is accompanied by intensive formation of volatiles $\left(\mathrm{CO}, \mathrm{H}_{2}\right)$ at the outlet of the gasifier (Fig. 2, b).

The intensive formation of volatilies in the gasifier during thermal decomposition of mw pretreated pellets shows the influence on the flow dynamics. Increasing the axial flow of volatiles at thermal decomposition of pretreated pellets promotes a decrease of the swirl intensity near the walls of the combustor (Fig. 3, a). This suggests intensive mixing of the axial flow of volatilies with swirling airflow completing combustion of volatiles and increasing the efficiency of energy production. As a 
result, for all types of mw pre-treated pellets the total heat output from the device increases: at thermochemical conversion of pretreated straw pellets the heat output increases by about $33 \%$, for wood by $26 \%$ and for peat by $24 \%$ (Fig. 3, b). Moreover, the produced heat energy per mass of mw pre-treated straw pellets increases by $23 \%$, wood pellets - by $18 \%$ and peat pellets - by $23 \%$ (Fig. 3, b). In addition, the results of the previous research have shown $[11,12]$ that mw pre-treatment of lignocellulosic biomass promotes increase of the heating values (LHV, HHV) and carbon content in the biomass. As a result, increased carbon content in mw pre-treated biomass, faster and higher thermal decomposition of pretreated pellets with intensive formation of volatiles are the main factors promoting enhanced formation of the main product $\left(\mathrm{CO}_{2}\right)$ during primary and self-sustaining combustion stages (Fig. 3, c).
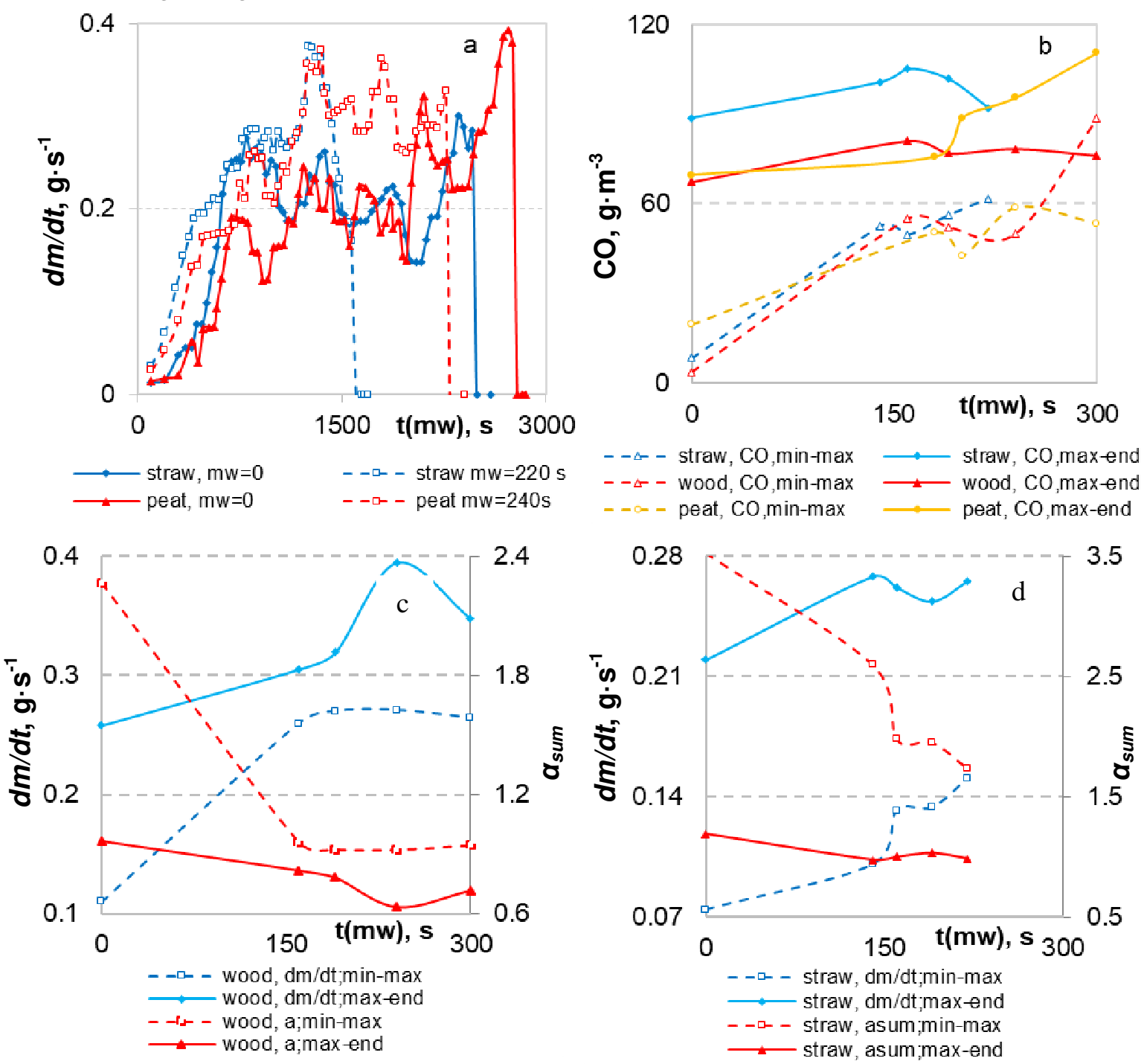

Fig. 2. Effect of straw, wood and peat pellet mw pre-treatment duration on the weight loss rates $(a, c, d)$, air excess rates $(c, d)$ and formation of volatiles (b) during thermal decomposition of pellets

The average value of $\mathrm{CO}_{2}$ emission in products is growing by $12 \%$ for mw pre-treated straw pellets, by $9 \%$ and $7 \%$ respectivelly for wood and peat pellets. However, as a negative result should be noticed an increase of the mass fraction of CO in the products (Fig. 3, d), which is mainly the result of intensive thermal decomposition of pre-treated pellets, decreasing the air excess in the flame reaction zone and determining the formation of fuel-rich conditions with $\alpha=0.7-0.8$ for wood and peat pellets (Fig. 2, c-d). With the aim to improve the combustion of pre-treated pellets and reduction of $\mathrm{CO}$ emission in the products, it is necessary to increase the secondary swirling air supply, which is confirmed by the preliminary results of the experimental study, when increasing the secondary air suplly up to $60 \mathrm{l} \cdot \mathrm{min}^{-1}$ allows to reduce the mass fraction of $\mathrm{CO}$ emissions with correlating increase of 
the air excess ratio in the flame reaction zone and the $\mathrm{CO}_{2}$ volume fraction in the products. It should be noticed that mw-pretreatment of pellets contributes to decrease of $\mathrm{NO}_{\mathrm{x}}$ emissions in the products by about $35 \%$. Currently the reson for the $\mathrm{NO}_{\mathrm{x}}$ decrease is unclear and will be futher investigated.
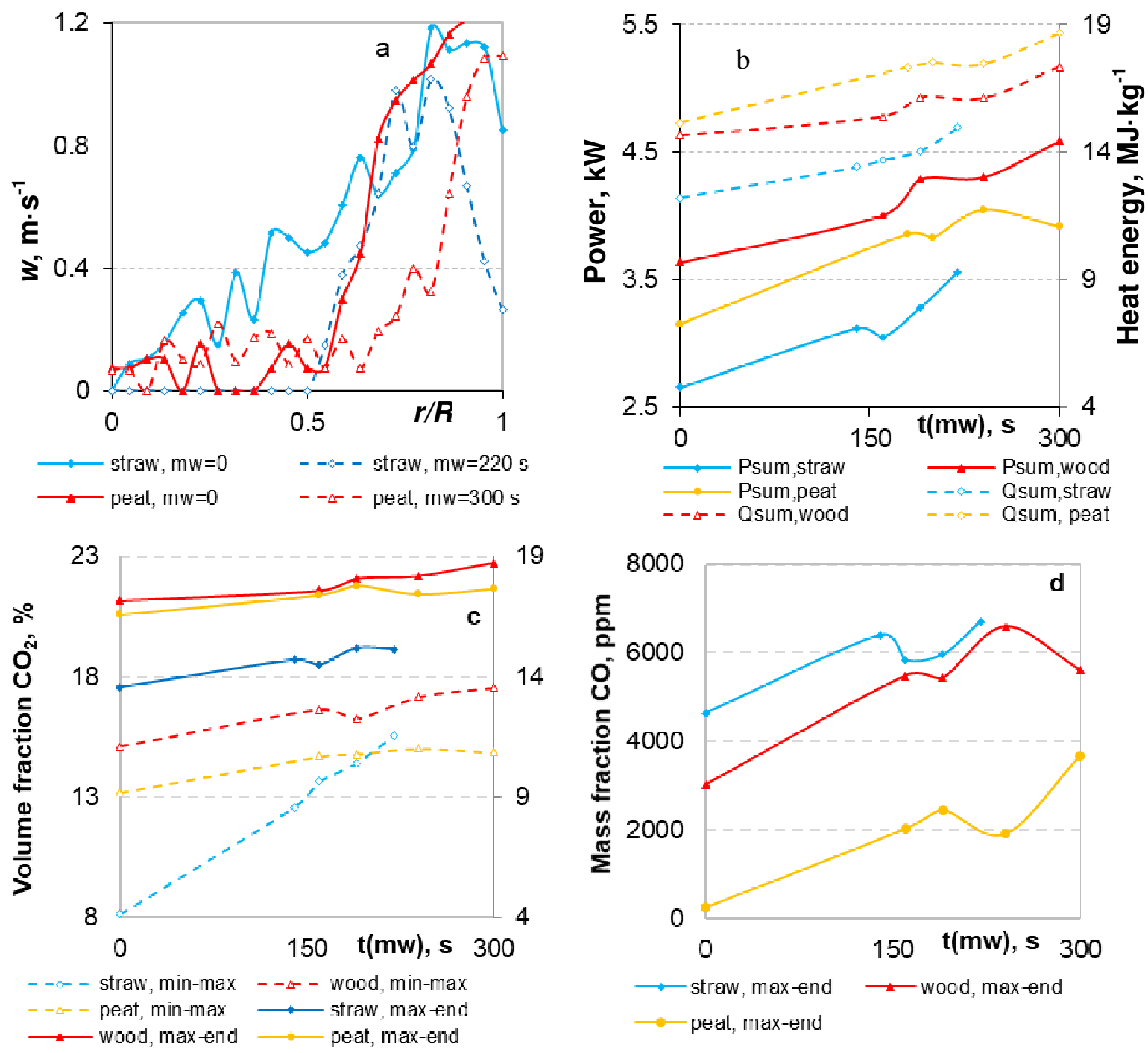

Fig. 3. Effect of mw pre-treatment duration of pellets on the tangential flow velocity (a), produced heat output from the setup and produced heat per mass of burned pellets (b); on formation of volume fraction of $\mathrm{CO}_{2}(\mathrm{c})$ and mass fraction of $\mathrm{CO}(\mathrm{d})$ in the products during thermal decomposition of straw, wood and peat pellets

\section{Conclusions}

From the experimental results presented above it follows that mw pre-treatment of straw, wood and peat pellets at different duration results in:

1. Partial destruction of the biomass structure promoting faster decomposition of pre-treated pellets with enhanced formation, ignition and burnout of combustible volatiles $\left(\mathrm{CO}, \mathrm{H}_{2}\right)$.

2. The enhanced formation and burnout of volatiles contributes to noticeable increase of the total heat output from the device and the produced heat energy per mass of burned biomass (for straw by $23 \%$, for wood by $18 \%$ and for peat by $23 \%$ ). Besides, the average value of $\mathrm{CO}_{2}$ emission in products increases by $12 \%$ for straw pellets, by $9 \%$ for wood pellets and $7 \%$ for peat pellets. Moreover, during combustion of mw pre-treated straw pellets NOx emissions in the products decrease up to $35 \%$. 
3. To reduce the mass fraction of $\mathrm{CO}$ emission in the products at thermochemical conversion of pretreated pellets, it is necessary to control the air supply in the combustion zone.

4. The mw pre-treatment of biomass is an effective tool for cleaner and effective energy production.

\section{Acknowledgements}

The authors would like to express their gratitude for financial support from the European Regional Funding for Project SAM 1.1.1.1./19/A/010.

\section{References}

[1] EU's 2030 policy framework, Clean Energy Package. 2018. [online][11.02.2020] Available at: https://www.eceee.org/policy-areas/2030-policy-framework/

[2] Liu T., McConkey B., Huffman T., Smith S., MacGregor B., Yemshanov D., Kulshreshtha S. Potential and impacts of renewable energy production from agricultural biomass in Canada. Appl. Energy, vol. 130, 2014, pp. 222-229. https://doi.org/10.1016/j.apenergy.2014.05.044

[3] Veijonen K., Vainikka P., Jarvinen T., Alakangas E. Biomass co-firing- an efficient way to reduce greenhouse gas. European Bioenergy Networks (EUBIONET), Finland, 2003, pp. 1-28. [online][11.02.2020] Available at: https://ec.europa.eu/energy/sites/ener/files/documents/2003_cofiring_eu_bionet.pdf

[4] Barmina I., Valdmanis R., Zake M. The effects of biomass co-gasification and co-firing on the development of combustion dynamics. Energy, vol. 146, 2018, pp. 4-12. DOI: 10.1016/j.energy.2017.04.140

[5] Agbor E.U. Biomass co-firing with coal and natural gas. Thesis Master of Science, University of Alberts, Department of Mechanical Engineering, Canada, 2015, p. 119, DOI: 10.7939/R3DJ58T7F.

[6] Barmina I., Kolmickovs A., Valdmanis R., Zake M., Kalis H., Marinaki M., Experimental Study and Mathematical Modelling of Straw Co-Firing with propane. Chemical Engineering Transactions, vol. 74, 2019, p. 19-24. DOI: 10.3303/CET1974004

[7] Barmina I., Kolmickovs A., Valdmanis R., Zake M., Vostrikovs S., Kalis H., Strautins U. Electric field effects on the Thermal Decomposition and Co-combustion of straw with solid fuel pellets. Energies, vol. 12 (8), 2019), DOI:10.3390/en12081522, 1-20.

[8] Kostas E.T, Beneroso D., Robinson J.P. The application of microwave heating in bioenergy: A review on the microwave pre-treatment and upgrading technologies for biomass. Renewable and Sustainable Energy Reviews, vol. 77, 2017, pp. 12-27. https://doi.org/10.1016/j.rser.2017.03.135

[9] Agu O.S., Tabil L.G., Dumonceaux T. Microwave-Assisted Alkali Pre-Treatment, Densification and Enzymatic Saccharification of Canola Straw and Oat Hull. Bioengineering (Basel), vol. 4 (2), 2017, pp. 1-32. doi: 10.3390/bioengineering4020025.

[10] Keshwani D.R., Cheng J.J. Microwave-Based Alkali Pretreatment of Switchgrass and Coastal Bermudagrass for Bioethanol Production. Biotechnology Progress, vol. 26 (3), 2010, pp. 644-652, doi: $10.1002 /$ btpr.371

[11] Agular-Reynosa A., Romani A., Rodriguez-Jasso R.M., Aguilar C.N., Carrote G., Ruiz H.A. Microwave heating processing as alternative of pretreatment in second-generation biorefinery: An overview. Energy Conversion and Management, vol. 136, 2017, pp. 50-65. http://dx.doi.org/10.1016/j.enconman.2017.01.004,

[12] Huang Y.F., Chiueh P.T., Lo S.L. A review on microwave pyrolysis of lignocellulosic biomass. Sustainable Environment Research, vol. 26, issue 3, 2016, pp. 103-109, https://doi.org/10.1016/j.serj.2016.04.012

[13] Barmina I., Kolmičkovs A., Valdmanis R., Vostrikovs S., Zake M., Thermo-chemical conversion of microwave activated biomass mixtures, JPCS-IOP-MMP, Journal IOP conference series: Materials Science and Engineering, 2018, pp. 1-9, DOI: 10.1088/1757-899X/355/1/012018.

[14] Barmina I., Valdmanis R., Zake M., Microwave pre-processing of biomass pellets for cleaner heat energy production. Proceedings of 25th European Biomass Conference and Exhibition (25 EUBCE), Stockholm, Sweden, 2017, pp. 1070-1081, DOI: 10.5071/25thEUBCE2017-3DO.3.5.

[15] Yang H., Yan R., Chen H., Lee D.H., Zheng Ch., 2007, Characteristics of hemicellulose, cellulose and lignin pyrolysis, Fuel, 86, pp. 1781-1788. 